\title{
SENSITIVITAS USAHATANI PISANG KEPOK DI DESA BANGUN HARJA DI KECAMATAN SERUYAN HILIR TIMUR KABUPATEN SERUYAN
}

\author{
(Sensitivity Farming Banana Kepok in Village Bangun Harja District \\ of Seruyan Hilir Timur of Seruyan Regency)
}

\section{Lili Winarti}

Program Studi Agribisnis Fakultas Pertanian Universitas Darwan Ali Jl. S. Parman Kuala Pembuang Kabupaten Seruyan Kalimantan Tengah

e-mail : liliwinarti14@gmail.com

\begin{abstract}
This study aimed to analyze the sensitivity of the bananas kepok farm in the village Bangun Harja District of Seruyan Hilir Timur Regency Seruyan. The method used is in sampling with simple random method (Simple Random Sampling), using the method slovin with a confidence level of 10\%, obtained samples of 74 banana growers, for represent the entire population of banana growers in the village Bangun Harja Kecamtan Seruyan Hilir Timur Regency Seruyan. Analysis of the data used is the analysis of qualitative and quantitative analysis, qualitative analysis performed to obtain a picture or descriptive farming bananas kepok and quantitative analysis was conducted to analyze the costs incurred for activities ranging from the cost of investment, operational, production to marketing and financial analysis used to knowing feasible or not his farming bananas kepok using the criteria for eligibility of investment are: Net Present Value (NPV), Internal rate of Return (IRR), Net Benefit Cost ratio (Net B / C), Payback Period and then performed a sensitivity analysis to determine the level of sensitivity to the changes in the farm scenario 1 and 2 were used. The results of the sensitivity analysis shows that the decline in selling prices of bananas kepok more sensitive than the increase in operating costs of farming bananas kepok and a decrease in selling prices of bananas kepok 20\%, would lead to farm bananas kepok not worth the effort views of NPV, IRR, Net B/C and Payback Period.
\end{abstract}

Keywords : sensitivity, farming, banana kepok

\begin{abstract}
Abstrak
Penelitian ini bertujuan untuk menganalisis sensitivitas usahatani pisang kepok di Desa Bangun Harja Kecamatan Seruyan Hilir Timur Kabupaten Seruyan. Metode yang dilakukan dalam pengambilan sampel dengan metode acak sederhana (Simple Random Sampling), dengan mengunakan metode slovin dengan tingkat kepercayaan $10 \%$ diperoleh sampel 74 orang petani pisang, untuk mewakili seluruh populasi petani pisang yang ada di Desa Bangun Harja Kecamatan Seruyan Hilir Timur Kabupaten Seruyan. Analisis data yang digunakan adalah analisis kualitatif dan analisis kuantitatif, analisis kualitatif dilakukan untuk memperoleh gambaran atau deskriftif usahatani pisang kepok dan analisis kuantitatif dilakukan untuk menganalisis biaya-biaya yang dikeluarkan selama kegiatan mulai dari biaya investasi, operasional, produksi sampai pemasaran dan Analisis finansial digunakan untuk mengetahui layak atau tidak nya usahatani pisang kepok dengan menggunakan kriteria-kriteria kelayakan investasi yaitu: Net Present Value (NPV), Internal Rate of Return (IRR), Net Benefit Cost Rasio (Net B/C), Payback Period dan kemudian dilakukan analisis sensitivitas untuk mengetahui tingkat kepekaan usahatani terhadap adanya perubahan dengan skenario 1 dan 2 yang digunakan, pada saja skenario 1 . Hasil analisis sensitivitas menunjukkan bahwa penurunan harga jual pisang kepok lebih sensitif dibandingkan dengan peningkatan biaya operasional usahatani pisang kepok dan penurunan harga jual pisang kepok 20\%, akan menyebabkan usahatani pisang kepok tidak layak untuk diusahakan dilihat dari NPV, IRR, Net B/C dan Payback Periodnya.
\end{abstract}

Kata kunci : sensitivitas, usahatani, pisang kepok 


\section{PENDAHULUAN}

Pisang Kepok (Musa acuminata balbisiana) merupakan produk yang cukup perspektif dalam pengembangan sumber pangan lokal, tanaman pisang banyak diusahakan oleh para petani dan juga keunggulan pisang ini dapat tumbuh di sembarang tempat sehingga produksi buahnya selalu tersedia, komoditas pisang merupakan salah satu tanaman unggulan di Kabupaten Seruyan dan dari data Statistik Pertanian, produksi pisang di Kabupaten Seruyan dari Tahun 2012 sampai Tahun 2014 mengalami peningkatan. Hal ini terbukti bahwa komoditi pisang di Kabupaten Seruyan menunjukan trend yang positif dari tahun ke tahun (BPS. 2015), dan untuk melihat nilai produksi buah pisang dari Tahun 2012 sampai Tahun 2014 di Kabupaten Seruyan dapat dilihat pada Tabel 1.

Kecamatan Seruyan Hilir Timur merupakan salah satu kecamatan yang paling banyak mengusahakan tanaman pisang terutama pisang kepok, dan dengan banyaknya petani yang mengusahakan usahatani pisang kepok, berimplikasi pada hasil yang nantinya diperoleh mengingat produk pertanian yang sifatnya musiman, tidak bertahan lama yang tentu saja memberikan peluang kepada para tengkulak untuk mempermainkan harga pisang kepok dan analisis sensivitas merupakan analisis yang dilakukan untuk mengetahui akibat dari perubahan parameter-parameter produksi terhadap perubahan kinerja system produksi dalam menghasilkan keuntungan agar nantinya petani pisang kapok memiliki gambaran tentang usahatani yang dilakukannya. Dengan melakukan analisis sentivitas maka akibat yang mungkin terjadi dari perubahanperubahan tersebut dapat diketahui dan diantisipasi sebelumnya oleh petani pisang kepok, Gittinger (1986) menyatakan bahwa suatu variasi pada analisis sensitivitas adalah nilai pengganti (switching value), switching value ini adalah perhitungan untuk mengukur perubahan maksimum. Perbedaan yang mendasar antara analisis sensivitas yang biasa dilakukan dengan switching value adalah pada analisis sensivitas besarnya perubahan sudah diketahui secara empirik. Penelitian ini bertujuan untuk menganalisis sensitivitas usahatani pisang kepok di Desa Bangun Harja Kecamatan Seruyan Hilir Timur Kabupaten Seruyan.

\section{TINJAUAN PUSTAKA}

Buah pisang kepok tersusun dalam tandan dengan kelompok-kelompok tersusun menjari yang disebut sisir, adapun klasifikasi pisang kepok (Tjitrosoepomo, 1998), adalah :

$$
\text { Kingdom : Plantae }
$$

Filum : Magnoliophta

Kelas : Magnoliopsida

Ordo : Zingiberalez

Famili : Musaceae

Genus : Musa

Spesies : Musa acuminate L.

Studi kelayakan pada akhir-akhir ini telah banyak dikenal oleh masyarakat yang bergerak dalam bidang dunia usaha. Bermacam-macam peluang dan kesempatan 
Tabel. 1. Data statistik pertanian produksi pisang tahun 2012 sampai tahun 2014

\begin{tabular}{clccc}
\hline \multirow{2}{*}{ No. } & \multicolumn{1}{c}{ Kecamatan } & \multicolumn{3}{c}{ Produksi (Ton) } \\
\cline { 2 - 5 } 1. & Seruyan Hilir & 128 & 108 & Tahun 2014 \\
2. & Seruyan Hilir Timur & 536 & 720 & 108 \\
3. & Danau Sembuluh & 112 & 96 & 746 \\
4. & Seruyan Raya & 100 & 92 & 96 \\
5. & Hanau & 12 & 12 & 92 \\
6. & Danau Seluluk & 44 & 32 & 12 \\
7. & Seruyan Tengah & 148 & 156 & 32 \\
8. & Batu Ampar & 96 & 80 & 156 \\
9. & Seruyan Hulu & 60 & 48 & 80 \\
10. & Suling Tambun & 24 & 16 & 48 \\
\hline & \multicolumn{1}{c}{ Jumlah } & $\mathbf{1 . 2 6 0}$ & $\mathbf{1 . 3 6 0}$ & $\mathbf{1 . 3 8 6}$
\end{tabular}

Sumber : Dinas Pertanian dan Peternakan Kabupaten Seruyan Tahun 2015

yang ada dalam kegiatan usaha telah menuntut pula adanya penilaian sejauh mana kegiatan/ kesempatan tersebut dapat memberikan manfaat (benefit) bila diusahakan. Kegiatan untuk menilai sejauh mana manfaat yang diperoleh dalam melaksanakan kegiatan suatu usaha/proyek disebut dengan kelayakan bisnis. Dengan demikian studi kelayakan yang sering juga disebut dengan feasibility study merupakan bahan pertimbangan dalam mengambil suatu keputusan, apakah menerima atau menolak dari suatu gagasan usaha/proyek yang direncanakan. Pengertian layak dalam penilaian ini adalah kemungkinan dari gagasan usaha/proyek yang akan dilaksanakan memberikan manfaat (benefit), baik dalam arti financial benefit, maupun dalam arti social benefit. Layaknya suatu gagasan usaha/ proyek dalam arti social benefit tidak selalu menggambarkan layak dalam arti financial benefit, hal ini tergantung dari penilaian yang dilakukan (Ibrahim, 2009).
Kriteria investasi menggunakan present value yang telah didiskonto dari arus-arus benefit dan biaya selama umur proyek. Aspek finansial yang dianalisis adalah Net Present Value (NPV), Internal Rate of Return (IRR), Net Benefit per Cost (Net B/C) dan Payback Period.

Menurut Ibrahim (2009), Net Present Value adalah kriteria investasi yang banyak digunakan dalam mengukur apakah suatu proyek layak atau tidak. Untuk menghitung NVP di dalam sebuah gagasan usaha (proyek) diperlukan data tentang perkiraan biaya investasi, biaya operasional, dan pemeliharaan serta perkiraan manfaat (benefit) dari proyek yang direncanakan.

Menurut Gittinger (1986), IRR adalah tingkat rata-rata keuntungan intern tahunan bagi perusahaan yang melakukan investasi dan dinyatakan dalam satuan persen. Tingkat IRR mencerminkan tingkat suku bunga yang dapat 
dibayar oleh proyek untuk sumberdaya yang digunakan. Suatu investasi dianggap layak apabila memiliki nilai IRR lebih besar dari tingkat suku bunga yang berlaku dan suatu investasi dianggap tidak layak apabila memiliki nilai IRR yang lebih kecil dari tingkat suku bunga yang berlaku.

Net Benefit and Cost Ratio (Net B/C) merupakan angka perbandingan antara present value dari net benefit yang positif dengan present value dari net benefit yang negatif. Payback Period merupakan analisis untuk mengetahui waktu pengembalian biaya investasi dan total biaya dari sebuah proyek yang dikembangkan (Ibrahim, 2009).

Analisis sensitivitas dilakukan untuk meneliti kembali analisis kelayakan proyek yang telah dilakukan, tujuannya yaitu untuk melihat pengaruh yang akan terjadi apabila keadaan berubah. Hal ini merupakan suatu cara untuk menarik perhatian pada masalah utama proyek yaitu proyek selalu menghadapi ketidakpastian yang dapat terjadi pada suatu keadaan yang telah diramalkan dan suatu variasi pada analisis sensitivitas adalah nilai pengganti (switching value).

\section{METODOLOGI}

Penelitian ini dilaksanakan di Desa Bangun Harja Kecamatan Seruyan Hilir Timur Kabupaten Seruyan dengan pertimbangan bahwa di Desa Bangun Harja Kecamatan Seruyan Hilir Timur merupakan desa yang paling banyak berusahatani pisang kepok.
Penelitian ini dilaksanakan pada bulan Juni 2016 sampai dengan Oktober 2016.

Metode penelitian yang digunakan yaitu metode yang dilakukan dalam pengambilan sampel dengan metode acak sederhana (simple random sampling). Dengan mengunakan Metode Slovin dengan tingkat kepercayaan $10 \%$, yang sebelumnya diketahui populasi petani pisang di Desa Bangun Harja adalah 279 orang petani pisang dan diperoleh sampel 74 orang petani pisang, untuk mewakili seluruh populasi petani pisang yang ada di Desa Bangun Harja Kecamtan Seruyan Hilir Timur Kabupaten Seruyan. Analisis data yang digunakan adalah analisis kualitatif dan analisis kuantitatif, Analisis kualitatif dilakukan untuk memperoleh gambaran atau deskriftif usahatani pisang kepok dan analisis kuantitatif dilakukan untuk menganalisis biaya-biaya yang dikeluarkan selama kegiatan mulai dari biaya investasi, operasional, produksi sampai pemasaran.

Beberapa asumsi dasar yang digunakan dalam penelitian Sensitivitas Usahatani Pisang Kepok di Kecamatan Seruyan Hilir Timur Kabupaten Seruyan yaitu: 1) pendapatan adalah total penerimaan yang diperoleh pengusaha setelah dikurangi total biaya dalam satuan $\mathrm{Rp} / \mathrm{kg}$ per tahun, 2) penerimaan adalah jumlah produksi dikali dengan harga yang dihitung dalam satuan $\mathrm{Rp} / \mathrm{kg}$ per tahun dengan asumsi semua produk terjual, 3) tahun dasar yang digunakan dalam penelitian ini adalah tahun 2015 , 4) modal yang digunakan diasumsikan modal sendiri, 5) umur proyek dari analisis 
kelayakan finansial usahatani adalah 10 tahun,

7) harga jual pisang kepok Rp 2.000 per kg,

8) umur ekonomis adalah depresiasi atau penyusutan dalam akuntansi adalah penyebaran biaya asal suatu aktiva tetap selama umur perkiraannya. 9) tingkat suku bunga (discount rate) adalah persentase dari pokok utang yang dibayarkan sebagai imbal jasa (bunga) dalam suatu periode tertentu. Tingkat suku bunga kredit yang digunakan adalah 9\% persen per tahun berdasarkan pada Kredit Usaha Rakyat (KUR) BRI, 10) analisis sensitivitas adalah analisis yang dilakukan untuk meneliti kembali sensitivitas usahatani pisang kepok yang telah dilakukan, tujuannya yaitu untuk melihat pengaruh yang akan terjadi apabila keadaan berubah atau kondisi berubah.

\section{Analisis Kelayakan Usahatani Pisang Kepok}

Pendapatan usahatani dilakukan dengan menggunakan analisis keuntungan bertujuan untuk mengetahui keuntungan usahatani pisang kepok

$$
\pi=\mathrm{TR}-\mathrm{TC}
$$

Keterangan:

$$
\begin{aligned}
\pi= & \text { Profit/Keuntungan }(\mathrm{Rp}) \\
\mathrm{TR}= & \text { Penerimaan Total }(\text { Total Revenue })(\mathrm{Rp}) \\
\mathrm{TC}= & \text { Biaya Total }(\text { Total Cost })(\mathrm{Rp}) \\
& (\text { Soekartawi, 1995) } .
\end{aligned}
$$

Untuk menghitung kelayakan usaha dan sensitivitas usahatani pisang kepok dapat menggunakan analisis finansial dengan kriteriakriteria kelayakan investasi yaitu:

\section{Net Present Value (NPV)}

$$
N P V=\sum_{i=1}^{n} \frac{N B i}{(1+i)^{n}}
$$

Keterangan:

$$
\begin{aligned}
& \mathrm{NB}= \text { net benefit } \text { (benefit cost) }=\text { Benefit }- \\
& \text { Cost } \\
& \mathrm{i}= \text { discount factor } \\
& \mathrm{n}= \text { umur ekonomis usaha (tahun) } \\
& \text { dengan kriteria sebagai berikut: }
\end{aligned}
$$

NPV $>0$, berarti suatu usaha layak diusahakan.

$\mathrm{NPV}=0$, tergantung dari tujuan usaha untuk dilaksanakan atau tidak.

$\mathrm{NPV}<0$, berarti usaha tidak layak diusahakan. (Ibrahim, Y. 2009).

\section{Internal Rate of Return (IRR)}

$$
I R R=i_{1}+\frac{N P V_{1}}{N P V_{1}-N P V_{2}} X\left(i_{2}-i_{1}\right)
$$

Keterangan :

$$
\begin{aligned}
\mathrm{NVP}_{1}= & \text { Nilai NVP yang positif } \\
\mathrm{NVP}_{2}= & \text { Nilai NVP yang negatif } \\
\mathrm{i}_{1}= & \text { Tingkat bunga pada saat NVP positif } \\
\mathrm{i}_{2}= & \text { Tingkat bunga pada saat NVP } \\
& \text { negatif }
\end{aligned}
$$

Kriteria dalam Internal Rate of Return :

IRR = tingkat suku bunga, dengan kata lain usaha tersebut dalam keadaan Break Even Point (BEP), proyek tersebut tidak untung maupun rugi.

IRR > tingkat suku bunga, artinya usahatani layak untuk dilaksanakan.

IRR < tingkat suku bunga, artinya usahatani tidak layak untuk dilaksanakan atau dengan kata lain proyek tersebut merugikan.

(Ibrahim, 2009). 
Net Benefit Cost Rasio (Net B/C)

Net $B / C=\frac{\sum_{i=1}^{n} N \bar{B}_{i}(+)}{\sum_{i=1}^{n} N \bar{B}_{i}(-)}$

$($ Untuk Bt $-\mathrm{Ct}>0)$

$N B C R=\frac{\sum_{t=1}^{n} \frac{B_{t-} C_{t}}{(1+i)^{t}}}{\sum_{t=1}^{n} \frac{B_{t-} C_{t}}{(1+i)^{t}}} \quad($ Untuk Bt $-\mathrm{Ct}<0)$

Keterangan :

\section{NBCR $=$ Net Benefit Cost Ratio}

$\mathrm{Bt}=$ Benefit pada tahun $\mathrm{t}$

$\mathrm{Ct}=$ Biaya proyek pada tahun $\mathrm{t}$

I = Tingkat suku bunga

$\mathrm{N}=$ Umur ekonomis proyek

Kriteria Net B/C Ratio ad alah:

Jika Net B/C >1, maka proyek atau usahatani layak untuk dilaksanakan.

Jika Net $\mathrm{B} / \mathrm{C}<1, \quad$ maka proyek atau usahatani tidak layak untuk dilaksanakan.

(Ibrahim, Y. 2009).

\section{Payback Period}

Payback Period $=\frac{\text { Investasi }}{\text { Keuntungan }} \times 1$ tahun

Payback Period $=\frac{I}{A b}$

Keterangan :

$\mathrm{I}=$ Besarnya investasi yang diperlukan

$\mathrm{Ab}=$ Benefit bersih yang dapat diperoleh setiap tahun

$P B P=T_{P-1}+\frac{\sum_{i=1}^{n} I_{i}-\sum_{i=1}^{n} B_{c p-1}}{B_{P}}$

Keterangan :

$\mathrm{PBP}=$ Payback Period

$\mathrm{T}_{\mathrm{p}-1}=$ Tahun sebelum terdapat Payback Period

$\mathrm{I}_{1} \quad=$ Jumlah investasi yang sudah didiscount
$\mathrm{B}_{\mathrm{cp}-1}=$ jumlah benefit yang didiscount sebelum Payback Period

$\mathrm{B}_{\mathrm{p}}=$ Jumlah benefit pada Payback Period (Ibrahim, Y. 2009).

\section{Analisis Sensitivitas}

Analisis sensitivitas digunakan untuk mengetahui tingkat kepekaan usaha terhadap adanya perubahan kondisi arus kas (kenaikan input, penurunan output, dan atau kenaikan input dan penurunan output secara bersamaan) (Ibrahim, Y. 2009). Adapun parameter yang digunakan pada analisis sensitivitas (switching value) adalah:

Skenario 1. Penurunan harga jual $(10 \%, 15 \%$, $20 \%)$.

Skenario 2. Peningkatan biaya variabel $(10 \%$, $15 \%, 20 \%)$.

\section{HASIL DAN PEMBAHASAN}

Lahan yang digunakan untuk penanaman pisang kepok di Desa Bangun Harja adalah status hak milik dengan cara membeli dengan harga Rp 25.000.000 per hektar, dan biaya investasi yang harus dikeluarkan oleh petani pisang kepok adalah membeli peralatan seperti cangkul, parang, sabit, handsprayer dan lanjung dengan jumlah total biaya peralatan adalah Rp 470.000. Untuk biaya operasional yang digunakan sebagai modal kerja seperti biaya input produksi dan tenaga kerja, biaya operasional tersebut terbagi ke dalam fixed cost dan variable cost, untuk fixed cost yang dikeluarkan pada usahatani pisang kepok adalah biaya penyusutan peralatan pertanian dengan 
jumlah total fixed cost adalah Rp 1.825.000, dan variabel cost dari usahatani ini antara lain membeli bibit, pupuk, pestisida dan upah tenaga kerja yang digunakan, dengan total variable cost adalah Rp11.860.000 yang terdiri dari biaya pembelian bibit, pembelian pupuk, pembelian pestisida dan ditambah biaya tenaga kerja yang digunakan (HKSP). Jadi, biaya operasional dikeluarkan pada awal usahatani adalah total biaya adalah Rp 12.042.500.

Besarnya penerimaan adalah hasil kali antara jumlah panen yang dihasilkan dengan harga per kg pisang kepok. Jumlah panen per hektar adalah banyaknya pohon pisang yang ditanam dikalikan dengan jumlah berat per tandan. Berat rata-rata pertandan dalam satu hektar adalah $12,5 \mathrm{~kg}$, sehingga jumlah panen per hektar adalah 400 batang x 12,5 kg adalah $5.000 \mathrm{~kg}$. Penerimaan yang diperoleh per hektar hasil kali antara berat panen per hektar $(\mathrm{kg})$ dengan harga rata-rata diterima petani yaitu $\mathrm{Rp}$ 2.000/kg sehingga besarnya penerimaan per hektar selama satu tahun adalah Rp 2.000 x $5.000 \mathrm{~kg}$, yaitu sebesar Rp 10.000.000.-, dan ini akan terjadi pada awal panen produksi pisang kepok karena biaya-biaya yang dikeluarkan pada awal usaha lebih besar, dan harga jual pisang kepok tergantung dari harga saat panen dan saat penelitian harga untuk pisang kepok rata-rata $\mathrm{Rp} 2.000$ per kg.

\section{Analisis Kelayakan Usahatani Pisang Kepok}

Berdasarkan hasil perhitungan analisis finansial dengan kriteri-kriteria penilaian investasi yang terdiri dari NPV, IRR, Net B/C,
Payback Period dan analisis sensitivitas dari usahatani pisang kepok maka diperoleh nilai untuk kelayakan yang disajikan pada Tabel 2 .

\section{Analisis Sensitivitas Usahatani Pisang Kepok}

Analisis sensitivitas yang digunakan bertujuan untuk melihat perubahan-perubahan yang terjadi pada usahatani pisang kepok di Desa Bangun Harja, berdasarkan hasil analisis sensitivitas pada skenario 1. Penurunan harga jual pisang kepok terjadi di tingkat petani sebagaimana disajikan pada Tabel 3.

Hasil sensitivitas pada penurunan harga sebesar 10\% (Rp 1.800 per $\mathrm{kg}$ ) menghasilkan nilai NPV positif, IRR lebih besar dari suku bunga yang berlaku (9\%), Net B/C lebih besar dari 1 dan payback period 9 tahun 4 bulan 20 hari, dan pada penurunan harga sebesar $20 \%$ menghasilkan nilai NPV negatif, IRR lebih kecil dari tingkat suku bunga dan Net B/C lebih kecil dari 1 dan payback period 9 tahun 10 bulan 24 hari.

Hasil sensitivitas pada peningkatan biaya operasional sebesar $15 \%$ menghasilkan nilai NPV positif, IRR lebih besar dari suku bunga yang berlaku (9\%), Net B/C lebih besar dari 1 dan payback period 9 tahun 3 bulan 5 hari, dan pada peningkatan biaya operasional sebesar $20 \%$ menghasilkan nilai NPV positif, IRR lebih besar dari tingkat suku bunga yaitu $11.4 \%$ dan Net B/C lebih besar dari 1 dan payback period 9 tahun 4 bulan 6 hari. 
Tabel 2. Rerata Perhitungan Kriteria Kelayakan Usahatani Pisang Kepok di Desa Bangun Harja Kecamatan Seruyan Hilir Timur Kabupaten Seruyan

\begin{tabular}{clc}
\hline No. & \multicolumn{1}{c}{ Kriteria Kelayakan } & Nilai \\
\hline 1. & Net Present Value (NPV) (Rp) & Rp 11.730.174 \\
2. & Internal Rate of Return (IRR) (\%) & $15,4 \%$ \\
3. & Net Benefit Cost Ratio (Net B/C) & 1,43 \\
4. & Payback Period & 8 Tahun 11 Bulan 23 Hari \\
\hline
\end{tabular}

Sumber : Pengolahan Data Primer Tahun 2016

Tabel 3. Rerata Perhitungan Sensitivitas Usahatani Pisang Kepok dengan Penurunan Harga Jual (Skenario 1) di Desa Bangun Harja Kecamatan Seruyan Hilir Timur Kabupaten Seruyan

\begin{tabular}{cccccc}
\hline \multirow{2}{*}{ Parameter } & \multirow{2}{*}{$\%$} & \multicolumn{4}{c}{ Kriteria Investasi } \\
\cline { 3 - 6 } & & NPV & IRR & Net B/C & Payback Period \\
\hline Penurunan harga jual & $10 \%$ & Rp 5.312.516 & $11.9 \%$ & 1,19 & 9 Tahun 4 Bulan 20 Hari \\
Penurunan harga jual & $15 \%$ & Rp 2.103.687 & $10,2 \%$ & 1,07 & 9 Tahun 7 Bulan 9 Hari \\
Penurunan harga jual & $20 \%$ & $-R p ~ 1.105 .142$ & $8.4 \%$ & 0.96 & 9 Tahun 10 Bulan 24 Hari \\
\hline
\end{tabular}

Sumber: Pengolahan Data Primer Tahun 2016

Tabel 4. Rerata Perhitungan Sensitivitas Usahatani Pisang Kepok dengan Peningkatan Biaya Operasional di Desa Bangun Harja Kecamatan Seruyan Hilir Timur Kabupaten Seruyan

\begin{tabular}{|c|c|c|c|c|c|}
\hline \multirow{2}{*}{ Parameter } & \multirow{2}{*}{$\%$} & \multicolumn{4}{|c|}{ Kriteria Investasi } \\
\hline & & NPV & IRR & Net $B / C$ & Payback Period \\
\hline $\begin{array}{l}\text { Peningkatan biaya } \\
\text { operasional }\end{array}$ & $10 \%$ & Rp 8.158.748 & $13,4 \%$ & 1,29 & 9 Tahun 2 Bulan 1 Hari \\
\hline $\begin{array}{l}\text { Peningkatan biaya } \\
\text { operasional }\end{array}$ & $15 \%$ & Rp 6.373 .035 & $12,3 \%$ & 1,22 & 9 Tahun 3 Bulan 5 Hari \\
\hline $\begin{array}{l}\text { Peningkatan biaya } \\
\text { operasional }\end{array}$ & $20 \%$ & $\operatorname{Rp} 4.587 .322$ & $11.4 \%$ & 1.16 & 9 Tahun 4 Bulan 6 Hari \\
\hline
\end{tabular}

Sumber : Pengolahan Data Primer Tahun 2016

Berdasarkan analisis sensitivitas yang dilakukan menunjukkan bahwa penurunan harga penjualan pisang kepok lebih sensitif, hal ini bisa dilihat ketika harga jual turun $20 \%$ yang sebelumnya harga pisang adalah Rp 2.000 per kg menjadi Rp 1.600 per kg maka petani pisang akan mengalami kerugian atau usahatani yang dijalankan tidak layak untuk diusahakan dilihat dari kriteria investasi yang digunakan.
Sensitivitas pada peningkatan biaya operasional usahatani khususnya pada biaya variabel yang digunakan pada skenario 2 yaitu peningkatan biaya operasional 10\%, $15 \%$ dan $20 \%$ usahatani masih layak sehingga usahatani pisang kepok masih layak untuk diusahakan. 


\section{SIMPULAN DAN SARAN}

\section{Simpulan}

Berdasarkan hasil penelitian yang diperoleh dapat disimpulkan bahwa :

1. Hasil analisis sensitivitas menunjukkan bahwa penurunan harga jual pisang kepok lebih sensitif dibandingkan dengan peningkatan biaya operasional usahatani pisang kepok.

2. Penurunan harga jual pisang kepok $20 \%$, akan menyebabkan usahatani pisang kepok tidak layak untuk diusahakan dilihat dari NPV, IRR, Net B/C dan Payback Period.

\section{Saran}

1. Petani pisang kepok hendaknya jangan menjual pisang kepoknya dengan harga di bawah Rp 1.700 rupiah, karena akan menyebabkan usahatani pisang kepok yang diusahakan akan mengalami kerugian atau menjadi tidak layak untuk diusahakan dilihat dari kriteria investasi (NPV, IRR, Net B/C dan Payback Period).

2. Hendaknya ada campur tangan dari pemerintah setempat yang melindungi petani dari harga yang ditetapkan oleh tengkulak pisang.

\section{DAFTAR PUSTAKA}

Badan Pusat Statistik. 2015. Seruyan Dalam Angka. Kabupaten Seruyan.

Badan Pusat Statistik (Dinas Pertanian dan Peternakan). 2015. http:seruyankab.bps.go.id. Kabupaten Seruyan.
Ibrahim, Y. 2009. Studi Kelayakan Bisnis. Edisi Revisi. Penerbit PT. Rineka Cipta. Jakarta.

Gittinger. 1986. Analisa Ekonomi ProyekProyek Pertanian. UI-Press Johns Hopkins Seri Edi dalam Pembangunan Ekonomi. Jakarta.

Soekartawi. 1995. Ilmu Usahatani. PT. Raja Grafindo Persada. Jakarta.

Tjitrosoepomo. 1998. Taksonomi Umum. Dasar-Dasar Taksonomi Tumbuhan. Gajah Mada University Press. Yogyakarta. 